\title{
Joaquín Torres García. Un moderno en la Arcadia
}

\author{
Museo Picasso Málaga \\ Del 11 de octubre de 2016 al 5 de febrero de 2017
}

Escultura, pintura, teoría, constructivismo, futurismo, tradición, modernidad, vanguardia, anacronismo, símbolo, infancia, primitivismo, abstracción, figuración, centro, periferia, identidad, migración, materialidad, rusticidad, reencuentro, conciliación. La complejidad de la obra de Joaquín Torres García (1874-1949) pone sobre la mesa conceptos aparentemente tan dispares como estos. Términos de ida y vuelta que interaccionan, que se repelen y que vuelven a unirse con una fuerza magnética. La obra de Joaquín Torres García nos hace replantear eternos debates: ¿abstracción o figuración?, ¿tradición o modernidad? Diatribas que caen en el sinsentido cuando interpretamos, por ejemplo, una de sus estructuras en blanco y negro. La obra de Torres García se desarrolla en un triángulo cuyos vértices vienen marcados por la temporalidad, la geografía y la forma.

Entre el 11 de octubre de 2016 y el 5 de febrero de 2017 el Museo Picasso Málaga presentó una retrospectiva dedicada al artista latinoamericano, la meta de un recorrido de tres etapas que partió desde Nueva York. Su curador, Luis Pérez-Oramas, propone un viaje por los grandes dilemas en Torres García mediante una amplia selección de obras que arrancan desde la Barcelona de principios del 1900 y que culmina en una Montevideo portuaria, tradicional y asfixiada en la búsqueda de su propia identidad. Al igual que el propio Torres García, su obra migra por una cartografía atemporal que baila con el anacronismo, permeable y al mismo tiempo impermeable a la contemporaneidad, porque, como justifica el propio comisario, «las formas son nómadas y viven solo cuando migran».

El ingreso a la exposición lo preside una obra que irradia el más inmaculado de los clasicismos, el fresco del muro meridional de Mon Rèpos, donde se representa La Tierra, Eneas y Pan, 1914, flanqueada por dos pequeñas construcciones arquitectónicas en madera realizadas en torno a ese año. El hecho de que estas dos obras nos recuerden el lararium familiar de una domus romana no es de extrañar (a modo anecdótico, cabe recordar que sus hijos se llamaban Olimpia, Augusto, Ifigenia y Horacio; y que su casa en Bar- celona estaba inspirada en una domus romana), porque el clasicismo tan evidente en estos años nunca se escapará de su obra.

Desde ese momento, un barrido visual nos transporta al ambiente cabaretero barcelonés de Els Quatre Gats, donde un Torres García se retrata a sí mismo como burgués de pipa y bombín. Por estos años Pablo Picasso compartía los mismos ambientes y compañías que el artista uruguayo, Barcelona era una ciudad moderna, cosmopolita, con un puerto muy activo, un lugar donde se estaba construyendo un gran templo cristiano que desafiaba cualquier historicismo. Torres García conoció la ciudad moderna en Barcelona, y fue allí precisamente donde queda fascinado por el skyline de altas chimeneas de ladrillo rojo y el estrepitoso ruido de la grúa y el engranaje, visiones que abordará desde perspectivas bien distintas en Nueva York y París. Estos paisajes urbanos se caracterizan por un cierto horror vacui, composiciones de vertiginosa verticalidad donde las líneas esbozan elementos que podemos identificar como escaleras, tejados, grúas, números, ruedas, tranvías, letras y relojes. Mosaicos urbanos como una suerte de abstracción híbrida, antesala del constructivismo que veremos unos años más adelante. Todo se cubre con una pátina salvaje de tierra y metal que nos recuerda al cromatismo grecorromano.

Durante los dos primeros años de la década de los veinte, Torres García vive en Nueva York, una ciudad cuyo ritmo le deslumbra, cuya vida él mismo imaginaba «múltiple, gigante, maquinística, dinámica y libre». En un primer momento la metrópoli le infunde fascinación y energía, pero más tarde experimentará desencanto y horror. En la exposición se dedica un espacio relevante a este breve intervalo de tiempo en el que Torres García comienza a realizar los juguetes Aladdin Toys, proyecto que quedará relegado a un segundo plano por la importancia que le cede a unos paisajes urbanos distintos, espacios donde se densifica la presencia de letras y números, calles en las que las gentes son parte del engranaje del consumismo, de la publicidad y de vitrinas repletas de información sobre la mejor oferta [1]. 


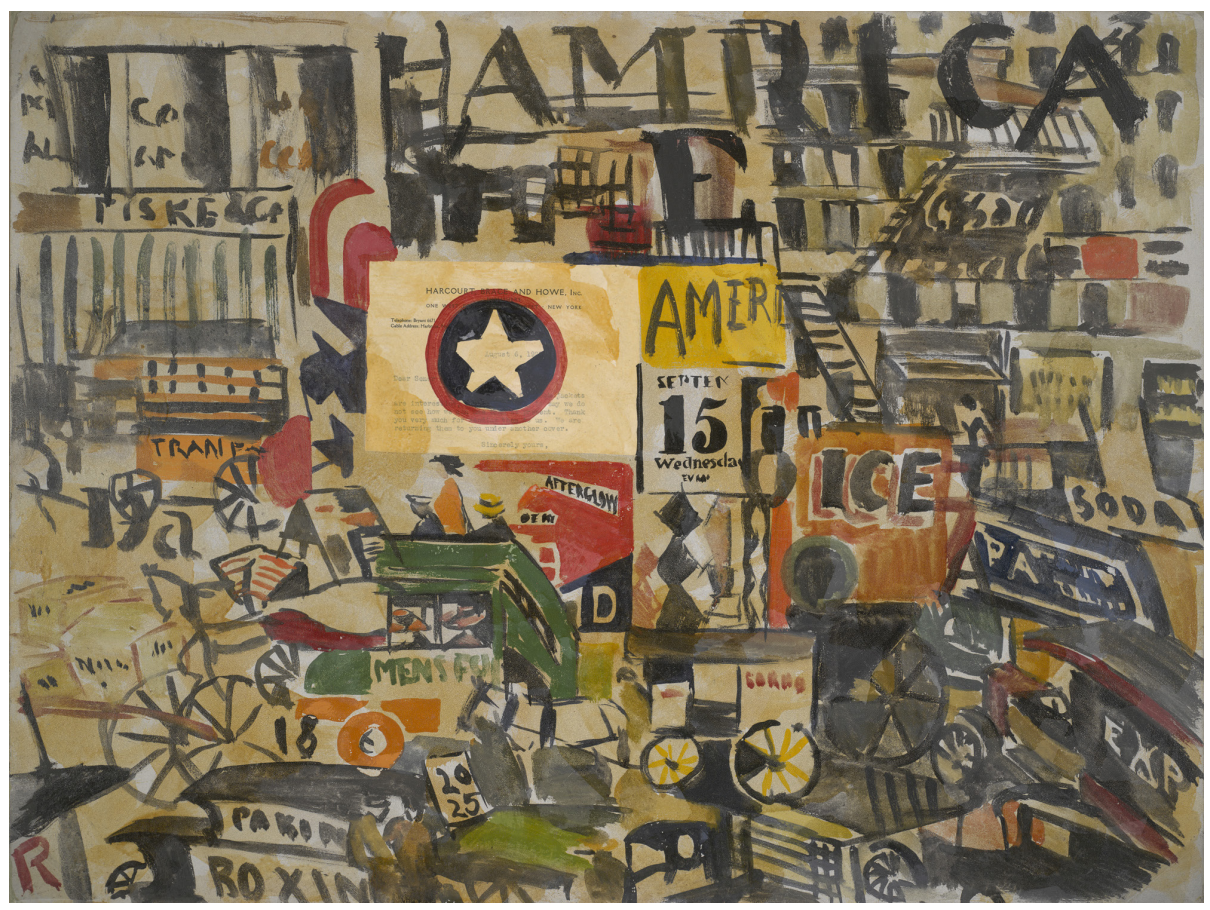

1. Joaquín Torres García. Calle de Nueva York, 1920

Tras algunos vaivenes por Italia el artista se traslada a París en 1926, rozaba la cincuentena y al fin creyó encontrar y encontró el lugar exacto en el momento justo. Allí se acercará al ambiente constructivista, trabajará con Mondrian, Arp, Vantongerloo, Léger, Kandinsky, Málevich y Russolo entre otros grandes representantes de los movimientos geométricos de vanguardia. Este momento culminará en 1930 con la inauguración en la Galerie 23 de la Première Exposition internationale du Groupe Cercle et Carré.

Pero Torres García no se siente cómodo en la abstracción y el neoplasticismo puro, las formas que articulan sus lienzos y tablas gozan de una materialidad y rusticidad sin parangón, jugando con la paleta de colores primarios de un modo sucio y sombrío. Para Torres García no existe oposición entre figuración y abstracción ya que todo se basa en la construcción: construye la paradójica Tête abstraite en 1929, que nos recuerda a la que hizo Kandinsky en ese mismo año (Empor, 1929, Colección Peggy Guggenheim, Venecia), Quatre figures rouges avec paysage, o Dos figuras misteriosas. En este momento también realiza numerosas composiciones sobre madera, donde se ensamblan planos de color rojo, blanco, azul o amarillo y en las que comienzan a aparecer pequeñas figuras esquemáticas, que nos dan sensación de profundidad entre una forma y otra.

Sorprendentemente es en París donde Torres García se mira en el espejo de América Latina, la identidad de su memoria es continental: asume formas y lenguajes comunes a la totalidad del pueblo latinoamericano y no necesariamente vinculados a las raíces de una nación (Uruguay). Así, Torres García excava en la estratigrafía de Sudamérica incorporando formas de la cultura indígena a partir del desarrollo nostálgico y evocador al que se somete cuando se enfrenta a los materiales de arqueología prehispánica de los grandes museos parisinos. Sus composiciones se tornan totémicas, cargadas de símbolos [2]; es el momento en el que la obra del artista encuentra una identidad, se define y llega a calar en el imaginario artístico colectivo.

Joaquín Torres García vivió la modernidad barcelonesa, neoyorquina y parisina, pero para él la modernidad no consistía en crear un tiempo nuevo, sino en identificar en el presente la manifestación de una temporalidad sedimental, porque las herencias culturales y por ende, artísticas, son 


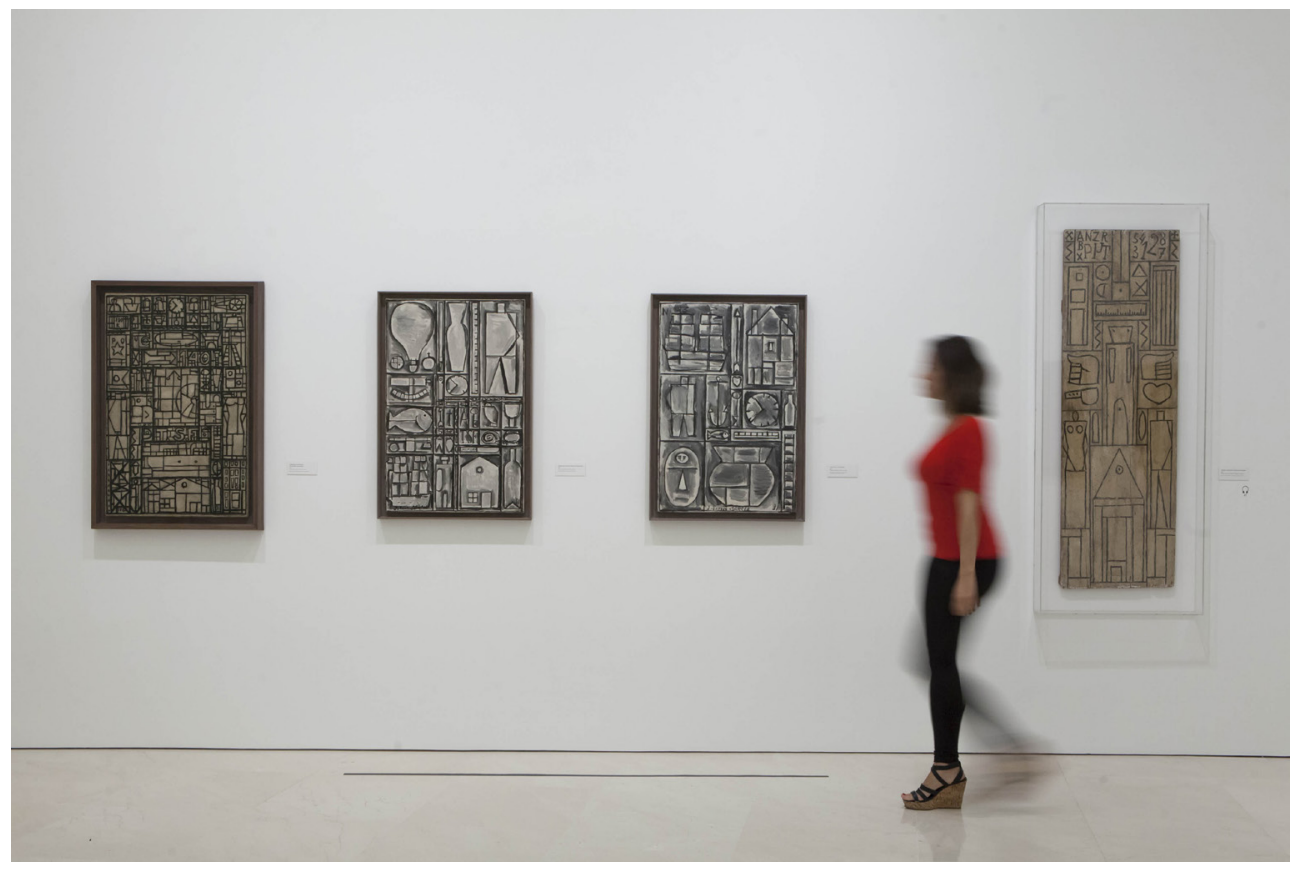

2. Vista de la exposición Joaquín Torres García. Un moderno en la Arcadia, en el Museo Picasso Málaga. @ Museo Picasso Málaga

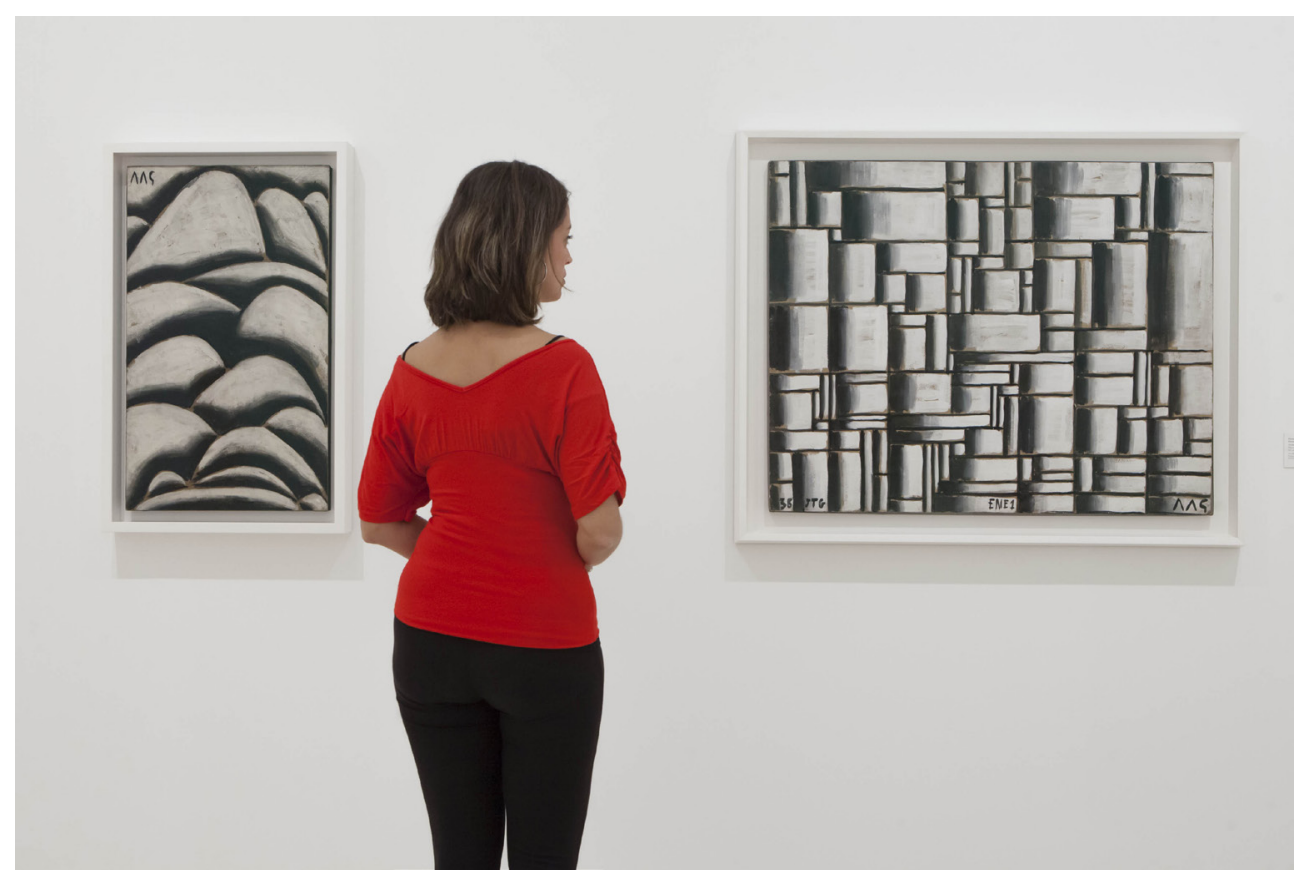

3. Vista de la exposición Joaquín Torres García. Un moderno en la Arcadia, en el Museo Picasso Málaga. @ Museo Picasso Málaga 
fruto de la historia, una historia lineal y diacrónica, consecutiva siglo tras siglo, año tras año, segundo tras segundo. El imaginario artístico colectivo se genera estratigráficamente, sólo a través de este proceso podremos hacer uso de una memoria artística que nos transporte en el tiempo, que produzca resultados complejos de interacción, sólo a través de la visión sedimentaria de la experiencia podemos utilizar el anacronismo. $Y$ en ese sentido, además de los trabajos de Aby Warburg, Walter Benjamin o Carl Jung, Joaquín Torres García nos propone su propio Atlas Mnemosine, con el título Structures, realizado en 1932. Un álbum de recortes donde se yuxtaponen imágenes que interaccionan, diálogos imposibles hechos posibles, fotogramas libres que van adelante y hacia atrás en el eje cronológico, un ensayo gráfico donde un barco y el interior de una catedral gótica pueden situarse en una misma página. Este tratado sobre la temporalidad no sólo se pudo ver por primera vez en la exposición, sino que además fue posible consultarlo mediante un dispositivo táctil permitiéndonos poder pasar sus páginas y desgranar las más sorprendentes analogías.

La muestra continuaba su desarrollo con una sala dedicada a sus pinturas en blanco y negro [3], obras que se corresponden con sus primeros años en Montevideo tras haber abandonado París y Madrid (tras el estancamiento de la economía francesa en torno a 1932, Joaquín Torres García se había trasladado a Madrid, donde conoce los ambientes de la Real Academia de Bellas Artes de San Fernando, realiza algunos encargos y donde se le dedica una retrospectiva). Estas composiciones podrían recordarnos al constructivismo de sus contemporáneos de Cercle et Carré, pero en este caso gozan del arraigo indoamericano de los pétreos muros de la ancestral ciudad preincaica de Tiahuanaco (Bolivia), o de la fortaleza ceremonial inca de Sacsayhuamán (Perú).

El debate torresgarciano se vuelve aún más complejo cuando llegamos a este momento de su vida. Tras más de cuarenta años en el extranjero, Joaquín Torres García intenta promover el arte moderno en Uruguay llevando a cabo una serie de iniciativas intelectuales que abarcan desde conferencias o apertura de estudios hasta la realización de exposiciones. El asunto es mucho más profundo, se trataba de la búsqueda de una identidad artística, de asociar una estética a un país. Se consiguió, el lenguaje se popularizó y democratizó, tomó símbolos como el ancla, el sol o incluso el mapa de América invertida como emblemas de un país, un colorido imaginario que hoy está realmente asumido por un pueblo, un pez que al igual que la paloma picassiana se alza como verdadero icono de su identidad cultural. La impronta torresgarciana fue y sigue siendo tan intensa en el arte contemporáneo uruguayo que imposibilita el parricidio de Torres, huir de él. Entre los principales logros de esta exposición no solo estuvo el hecho de inaugurar un puente artístico entre Latinoamérica y Málaga sino hacer legible la complejidad de un personaje huidizo, inclasificable y migrante.

Ramón Melero Guirado 